\title{
Amino acid requirements for maturation of rhesus monkey (Macacca mulatta) oocytes in culture
}

\author{
P. Zheng ${ }^{1,3}$, B. D. Bavister ${ }^{2,3}$ and W. Z. Ji $\mathrm{j}^{1,3 *}$ \\ ${ }^{1}$ Department of Reproductive Biology, Kunming Institute of Zoology, Chinese Academy of \\ Sciences, 32 jiao Chang Dong Lu, Kunming, Yunnan 650223, China; ${ }^{2}$ Audubon Institute \\ Center for Research of Endangered Species, 14001 River Road, New Orleans, LA 70131, \\ USA; ${ }^{3}$ China-US Primate Biology laboratory, Kunming Institute of Zoology, Chinese \\ Academy of Sciences, Kunming, Yunnan 650223, China
}

This study evaluated the effects of different amino acid formulations on supporting meiotic and cytoplasmic maturation of rhesus monkey (Macacca mulatta) oocytes in vitro. Five hundred and forty-six cumulus-oocyte complexes (COCs) aspirated from unstimulated adult monkey follicles ( $\geqslant 1000 \mu \mathrm{m}$ in diameter) were cultured in either modified Connaught Medical Research Laboratories 1066 medium (mCMRL-1066) or in one of eight chemically defined media (modified basic medium 5 supplemented with 5.5 mmol glucose $\mathrm{I}^{-1}, 0.003 \mathrm{mmol}$ pantothenic acid $\mathrm{I}^{-1}$ and different amino acid formulations) as below: (1) modified basic medium 5 (mBM5) containing no amino acid; (2) $\mathrm{mBM5}+0.2$ mmol glutamine $\mathrm{I}^{-1}$; (3) $\mathrm{mBM5}+11$ amino acids from hamster embryo culture medium 6 (HECM-6) (11 AA); (4) mBM5 + Eagle's non-essential amino acids (NEA); (5) mBM5 + NEA + 0.2 mmol glutamine $\mathrm{I}^{-1}$; (6) mBM5 + Eagle's essential amino acids (EA) without glutamine; (7) $\mathrm{mBM} 5+\mathrm{EA}+0.2 \mathrm{mmol}$ glutamine $\mathrm{I}^{-1} ;(8) \mathrm{mBM} 5$ + Eagle's 20 amino acids (20 AA) + $0.2 \mathrm{mmol}$ glutamine $\mathrm{I}^{-1}$; and (9) mCMRL-1066 (control). All media contained $\mathrm{FSH}$, LH, oestradiol and progesterone. After maturation, mature oocytes were subjected to the same fertilization and embryo culture procedures. COCs matured in treatment 5 had greater potential to progress to metaphase II $(66 \% ; P<0.05)$ than did those in treatments $1(37.3 \%), 2(48.3 \%), 3(41 \%), 6(41 \%)$ and $9(43 \%)$. Oocytes matured in treatment 8 had the best morula $(53 \%)$ and blastocyst $(18 \%)$ developmental responses $(P<0.05)$. The lowest $(P<0.05)$ morula and blastocyst developmental responses were obtained from COCs matured in treatments $1(0 \%)$ and $6(8 \%)$. The other media supported intermediate embryonic development (range $11-38 \%$ of morula and blastocyst). These results indicate that the choice of amino acids affects the competence of oocyte maturation and that Eagle's 20 AA with $0.2 \mathrm{mmol}$ glutamine $\mathrm{I}^{-1}$ is more efficient than the other amino acid formulations for maturation of rhesus monkey oocytes.

\section{Introduction}

Successful oocyte maturation, defined as the potential of oocytes to undergo normal embryonic development, involves not only nuclear events (completion of meiotic maturation), but also cytoplasmic maturation, which is poorly understood (Eppig et al., 1994). The importance of cytoplasmic maturation has been well recognized, but the underlying molecular, biochemical and physiological processes are far from clear, particularly in primates. The developmental potential of primate oocytes matured in vitro is remarkably inferior to that of in vivo matured oocytes (Wolf et al., 1989; Cha et al., 1991; Morgan et al., 1991; Barnes et al., 1995) and to that of in vitro matured oocytes from other species, including cows (Rose-Hellekant et al., 1998), sheep (Guler et al., 2000), pigs (Abeydeera et al., 2000), rats (Vanderhyden and Armstrong, 1990) and mice

*Correspondence

Email:wji@mail.kiz.ac.cn
(De La Fuente et al., 1999). This lack of developmental potential is primarily due to lack of knowledge about nutritional requirements of primate oocytes for supporting their maturation in vitro.

Studies have shown that the components of oocyte maturation medium involved in metabolism, such as energy substrates and nutrients, play important roles from oocyte maturation to preimplantation embryo development (RoseHellekant et al., 1998; Watson et al., 2000; Zheng et al., 2001a). In rodents and cattle, oocyte maturation and embryo development could be influenced significantly by a different selection of amino acid components in the culture medium (Bae and Foote, 1975a; Bavister and Arlotto, 1990; Avery et al., 1998; Rose-Hellekant et al., 1998). However, the nuclear and developmental competences of oocytes matured with different selections of amino acids are totally unknown in primates.

In vitro maturation (IVM) of mammalian oocytes is generally performed in culture medium supplemented with serum, follicular fluid, conditioned culture medium or serum 
albumin. It is well known that these undefined components make it very difficult to determine the optimal metabolic and nutritional requirements of the oocytes during maturation. The use of chemically defined culture media that eliminate these components facilitates studies aimed at examining mechanisms involved in the initiation and completion of successful oocyte maturation. We have established a chemically defined culture system, hamster embryo culture medium 10 (HECM-10) supplemented with glucose, progesterone, oestradiol and gonadotrophins for IVM of oocytes from unstimulated rhesus monkeys (Zheng et al., 2001a). This culture system was used in the present study to evaluate the ability of different combinations of amino acids to support maturation of rhesus monkey oocytes with the potential to undergo preimplantation embryonic development after in vitro fertilization (IVF).

\section{Materials and Methods}

\section{Animals and oocyte recovery}

Ovaries were collected on seven different days from healthy adult rhesus monkeys (Macaca mulatta) that were killed for industrial vaccine production. These animals had not been used for any experiment or received any treatment related to vaccine production. Ovaries collected on each day were used for one replicate of the study. The monkeys had normal menstrual cycles but the stages of the cycle were unknown at the time of use. Ovaries without apparent corpora lutea were excised and collected into Tyrode's albumin lactate pyruvate (TALP)-Hepes medium (Bavister, 1989) and transported to the laboratory at approximately $35^{\circ} \mathrm{C}$ within 1-2 h. Ovaries with active corpora lutea were excluded because cumulus-oocyte complexes (COCs) from these ovaries were of variable quality. Healthy follicles $\geqslant$ $1000 \mu \mathrm{m}$ in diameter were punctured to release oocytes into TALP-Hepes medium at $35^{\circ} \mathrm{C}$.

\section{In vitro maturation of oocytes}

Oocytes that appeared normal (non-vesiculated, round, and medium to lightly pigmented), contained an intact nuclear membrane, and were surrounded by several layers of tightly condensed cumulus cells (COCs) were used in the study. COCs from each animal were assigned randomly and matured in the following media: (1) basic medium 5 (BM5) supplemented with $5.5 \mathrm{mmol}$ glucose $\mathrm{I}^{-1}$ and $0.003 \mathrm{mmol}$ pantothenic acid $\mathrm{I}^{-1}$ (modified BM5 (mBM5)) (Lane et al., 1998; McKiernan and Bavister, 2000; Zheng et al., 2001a) (Table 1); (2) mBM5 + 0.2 mmol glutamine $\mathrm{I}^{-1}$; (3) mBM5 + 11 amino acids as in hamster embryo culture medium 6 (HECM-6) (mBM5 + 11 AA) (McKiernan and Bavister, 2000) (Table 2); (4) mBM5 + non-essential amino acids as in Eagle's minimal essential medium (NEA) (Eagle, 1959) (Table 2); (5) mBM5 + NEA + 0.2 mmol glutamine $\mathrm{I}^{-1}$; (6) mBM5 + essential amino acids as in Eagle's minimal essential medium (EA) without $0.2 \mathrm{mmol}$ glutamine $\mathrm{I}^{-1}$
(Eagle, 1959) (Table 2); (7) mBM5 + EA with $0.2 \mathrm{mmol}$ glutamine $\mathrm{I}^{-1}$; (8) mBM5 + Eagle's 20 amino acids (20 AA) with 0.2 mmol glutamine $\mathrm{I}^{-1}$; (9) control medium: modified Connaught Medical Research Laboratories1066 medium (mCMRL-1066) (Boatman, 1987). Single-strength NEA and EA without glutamine were made from respective 100 strength and 50-strength concentrated stocks (Gibco, Grand Island, NY). The osmolarities of all the media were 286-289 mOsmol kg-1. Medium mCMRL-1066 was used as the control because it could support IVM of rhesus monkey oocytes from non-stimulated females to produce blastocysts in vitro (Schramm and Bavister, 1996; Zheng et al., 2001a).

Maturation medium droplets were covered with salineequilibrated paraffin oil (Sigma, St Louis, MO) in a $60 \mathrm{~mm}$ plastic Petri dish (Falcon Plastics, Franklin lakes, NY, No. 1007) and equilibrated for $4 \mathrm{~h}$. The COCs were washed four times in the respective culture medium before IVM. Five to ten COCs were placed in $50 \mu \mathrm{l}$ drops of maturation medium and cultured for $36 \mathrm{~h}$ at $37^{\circ} \mathrm{C}$ in $5 \% \mathrm{CO}_{2}$ and air with $100 \%$ humidity. All media were supplemented with $3 \mu \mathrm{g}$ progesterone $\mathrm{ml}^{-1}$ (Sigma), $100 \mathrm{ng}$ oestradiol $\mathrm{ml}^{-1}$ (Sigma), $5 \mu \mathrm{g}$ ovine FSH ml-1 (oFSH-NIADDK-NIH, AFP55518) and $10 \mu \mathrm{g}$ ovine $\mathrm{LH} \mathrm{m}^{-1}$ (oLH-NIADDK-NIH, AFP4117A) as reported by Schramm and Bavister (1996) and Si et al. (2000).

\section{Evaluation of cumulus expansion and meiotic maturation}

At the end of IVM culture, the extent of cumulus expansion was assessed subjectively under a stereomicroscope and classified into five categories: (i) category 0: no expansion; (ii) category 1: very slight expansion observed only in the outermost layer; (iii) category 2: slight expansion observed in two to three layers from the periphery; (iv) category 3: moderate expansion, observed on about $50 \%$ of the cumulus cell layers; and (v) category 4: full expansion except in the corona radiata layer. After removing some of the cumulus layer by drawing COCs through a narrow Pasteur pipette to facilitate morphological observation, oocytes were examined under the microscope for the status of nuclear maturation. Extrusion of the first polar body (metaphase II (MII)) was considered as indicating completion of nuclear maturation. Oocytes could not be stained to verify MII chromosome configurations because this would have precluded developmental studies.

\section{IVF and embryo culture}

Ova at MII in all groups were subjected to the same IVF and embryo culture procedures. Semen was collected by penile electroejaculation (Gould and Mann, 1988) under sedation with ketamine $\mathrm{HCl}$ (4-5 $\mathrm{mg} \mathrm{kg}^{-1}$, i.m.; Xingan, Shanghai). Approval for the electroejaculation process was obtained from the Laboratory Animal Service at Kunming Institute of Zoology, Chinese Academy of Sciences. Sperm capacitation and IVF were performed as described by 
Table 1. Formulation of modified basic medium 5 (mBM5)

\begin{tabular}{ll}
\hline Component & Concentration $\left(\mathrm{mmol} \mathrm{I}^{-1}\right)$ \\
\hline $\mathrm{PVA}$ & $\left(0.1 \mathrm{mg} \mathrm{m}^{-1}\right)$ \\
$\mathrm{NaCl}$ & 113.8 \\
$\mathrm{KCl}$ & 3.0 \\
$\mathrm{CaCl}_{2}$ & 1.0 \\
$\mathrm{MgCl}_{2}$ & 2.0 \\
$\mathrm{NaHCO}_{3}$ & 25.0 \\
$1 \mathrm{~mol} \mathrm{HCl} \mathrm{I}^{-1}$ & $(140 \mu \mathrm{l}$ per $100 \mathrm{ml})$ \\
Lactate & $(64.8 \mu \mathrm{l}$ per $100 \mathrm{ml})$ \\
Glucose & 5.5 \\
Pantothenic acid & 0.003 \\
\hline
\end{tabular}

PVA: polyvinyl alcohol.

Bavister et al. (1983). In brief, washed motile spermatozoa were resuspended at $20 \times 10^{6} \mathrm{ml}^{-1}$ in $200 \mu \mathrm{l}$ drops of TALP medium (containing fraction $\mathrm{V}$ BSA), overlaid with paraffin oil in a $60 \mathrm{~mm}$ plastic Petri dish and incubated for $>4 \mathrm{~h}$ at $37^{\circ} \mathrm{C}$ in a humidified atmosphere of $5 \% \mathrm{CO}_{2}$ in air. Spermatozoa were incubated for an additional 1.0-1.5 h in the presence of $1.0 \mathrm{mmol} \mathrm{I}^{-1}$ each of dibutyryl cyclic AMP (dbcAMP; Sigma) and caffeine (Sigma) for hyperactivation (Boatman and Bavister, 1984). Hyperactivated spermatozoa were then diluted to $1 \times 10^{5}$ spermatozoa $\mathrm{ml}^{-1}$ in $100 \mu \mathrm{l}$ drops of TALP medium containing $2 \%$ bovine calf serum (Hyclone Laboratories Inc, Logan, UT) and co-incubated with respective MII oocytes, segregated in the nine treatments, for $12-16 \mathrm{~h}$ at $37^{\circ} \mathrm{C}$ in a humidified atmosphere of $5 \% \mathrm{CO}_{2}$ in air. After co-incubation, spermatozoa were removed manually by aspirating ova through a pulled glass pipette. Oocytes were examined for evidence of activation (presence of two polar bodies or more than one pronucleus). All polyspermic ova containing three or more pronuclei were excluded from the study.

The nine treatments were kept separate, and normal putative embryos (activated ova) were washed and cultured in $50 \mu \mathrm{l}$ drops of mCMRL-1066 containing $20 \%$ bovine calf serum at $37^{\circ} \mathrm{C}$ in a humidified atmosphere of $5 \% \mathrm{CO}_{2}, 5 \%$ $\mathrm{O}_{2}$ and $90 \% \mathrm{~N}_{2}$. Embryos were placed into fresh culture medium every other day until developmental arrest or hatching, and examined daily under a Nikon Diaphot TMD microscope ( $\times$ 200-400 magnification). Embryos with a blastocoel were classified as blastocysts.

\section{Statistical analysis}

Values for MII were analysed as the percentages of total oocytes, and values for activated ova and all stages of embryos were analysed as the percentages of MII ova. All percentage data were subjected to arcsin (square root) transformation. The transformed data were analysed by ANOVA and Fisher's protected least significant difference (LSD) test. Values with $P \leqslant 0.05$ were considered significant.

\section{Results}

A total of 546 morphologically normal COCs were retrieved in seven replicates and used in this study.

\section{Effect of maturation media on cumulus expansion and nuclear maturation of COCs}

After 36 h of IVM, there were significant treatment effects on cumulus expansion. Most COCs matured in treatments containing no amino acid or EA with or without glutamine (treatments 1, 6 and 7, respectively) displayed minimal cumulus expansion of category 1. Those in treatments 3 (containing $11 \mathrm{AA}$ ) and 9 (control) displayed maximal cumulus expansion of category 3. The cumulus expansion of COCs matured in treatment 4 (containing NEA without glutamine) was category 2 (slight expression). COCs in treatments 2 (mBM5 + glutamine), 5 (mBM5 + NEA + glutamine) and 8 (mBM5 + $20 \mathrm{AA}+$ glutamine) showed similar cumulus expansion of category 2-3 (slight to moderate expression).

Oocytes matured in treatment 5 (mBM5 + NEA + glutamine) displayed greater potential to progress to MII $(66 \%$, $P<0.05)$ than did oocytes matured in treatments 1 (mBM5 no amino acids, 37.3\%), 2 (mBM5 + glutamine, 48.3\%), 3 $(\mathrm{mBM} 5+11$ AA, 41\%), 6 (mBM5 + EA, 41\%) and 9 (mCMRL-1066, 43\%). No other comparison was significant (treatments 4 (mBM5 + NEA): 61\%; 7 (mBM5 + EA + glutamine): 59\%; 8 (mBM5 + 20 AA + glutamine): 56\%, respectively) (Table 3 ).

\section{Effects of different IVM treatments on oocyte fertilization and embryo development}

The abilities of oocytes matured in all treatments to undergo fertilization (range 64-94\%) and cleavage (range 56-82\%) were not significantly different (Table 3). However, the capabilities of ova to develop to more than the eight-cell, to at least the morula stage, and to blastocysts were significantly different $(P<0.05)$. In brief, ova in treatments 5 (mBM5 + NEA + glutamine, 56\%) and 8 $(\mathrm{mBM} 5+20 \mathrm{AA}+$ glutamine, 65\%) were more competent than those in treatments 1 (mBM5 no amino acids, $35 \%$ ) and 7 (mBM5 + EA + glutamine, 31\%) to develop beyond the eight-cell stage. Morula development in treatment 8 (mBM5 + $20 \mathrm{AA}+$ glutamine, 53\%) was better $(P<0.05)$ than development in treatments 1 (mBM5 no amino acids, $0 \%), 2$ (mBM5 + glutamine, 34\%), 4 (mBM5 + NEA, 30\%), 5 (mBM5 + NEA + glutamine, 26\%), 6 (mBM5 + EA, 8\%), 7 (mBM5 + EA + glutamine, $11 \%$ ) and 9 (mCMRL-1066, $38 \%)$, but did not significantly differ from that in treatment 3 $(36 \%)$. COCs matured in treatment 8 (mBM5 + $20 \mathrm{AA}+$ glutamine, $18 \%$ ) had greater potential than those matured in the other eight treatments (range $0-4 \%$ ) to progress to the blastocyst stage $(P<0.05)$.

The time interval for blastocyst formation was about $216 \mathrm{~h}$ in treatment $2,180 \mathrm{~h}$ in treatment $3,156-168 \mathrm{~h}$ in 
Table 2. Compositions of 11 amino acids from hamster embryo culture medium 6 (HECM-6), Eagle's non-essential amino acids and Eagle's essential amino acids without glutamine

\begin{tabular}{|c|c|c|c|c|c|}
\hline $\begin{array}{l}\text { HECM-6 } 11 \\
\text { amino acids }\end{array}$ & $\begin{array}{l}\text { Concentration } \\
\left(\mathrm{mmol} \mathrm{\textrm {I } ^ { - 1 } )}\right.\end{array}$ & $\begin{array}{l}\text { Eagle's non-essential } \\
\text { amino acids }\end{array}$ & $\begin{array}{l}\text { Concentration } \\
\left(\mathrm{mmol} \mathrm{\textrm {I } ^ { - 1 } )}\right.\end{array}$ & $\begin{array}{l}\text { Eagle's essential } \\
\text { amino acids }\end{array}$ & $\begin{array}{l}\text { Concentration } \\
\left(\mathrm{mmol} \mathrm{I}^{-1}\right)\end{array}$ \\
\hline Taurine & 0.50 & Alanine & 0.1 & Arginine & 0.6 \\
\hline Asparagine & 0.01 & Asparagine & 0.1 & Cysteine & 0.1 \\
\hline Cysteine & 0.01 & Aspartic acid & 0.1 & Histidine & 0.2 \\
\hline Histidine & 0.01 & Glutamic acid & 0.1 & Isoleucine & 0.4 \\
\hline Lysine & 0.01 & Glycine & 0.1 & Leucine & 0.4 \\
\hline Proline & 0.01 & Proline & 0.1 & Lysine & 0.4 \\
\hline Serine & 0.01 & Serine & 0.1 & Methionine & 0.1 \\
\hline Aspartic acid & 0.01 & & & Phenylalanine & 0.2 \\
\hline Glycine & 0.01 & & & Threonine & 0.4 \\
\hline Glutamic acid & 0.01 & & & Tryptophan & 0.5 \\
\hline \multirow[t]{2}{*}{ Glutamine } & 0.2 & & & Tyrosine & 0.2 \\
\hline & & & & Valine & 0.4 \\
\hline
\end{tabular}

Table 3. Meiotic competence and developmental potential of unstimulated adult rhesus monkey cumulus-oocyte complexes matured with different amino acid treatments

\begin{tabular}{|c|c|c|c|c|c|c|c|c|}
\hline \multirow[b]{2}{*}{ Treatment } & \multirow[b]{2}{*}{ Composition } & \multirow[b]{2}{*}{ Number } & \multirow[b]{2}{*}{ MII (\%)* } & \multicolumn{5}{|c|}{ Developmental stage reached $(\%) \dagger$} \\
\hline & & & & Fertilized & $>$ two-cell & > eight-cell & Morula & Blastocyst \\
\hline \multirow[t]{2}{*}{1} & \multirow[t]{2}{*}{ mBM5 } & \multirow[t]{2}{*}{59} & $22 / 59^{a}$ & $17 / 22$ & $13 / 17$ & $6 / 17^{a}$ & $0 / 17^{a}$ & $0 / 17^{a}$ \\
\hline & & & $(37.3 \pm 14)$ & $(77 \pm 21)$ & $(76 \pm 13)$ & $(35 \pm 23)$ & $(0 \pm 0)$ & $(0 \pm 0)$ \\
\hline \multirow[t]{2}{*}{2} & \multirow[t]{2}{*}{$\mathrm{mBM} 5+\mathrm{GLN}$} & \multirow[t]{2}{*}{60} & $29 / 60^{a}$ & $26 / 29$ & $22 / 29$ & $16 / 29^{a b}$ & 10/29be & $1 / 29^{a}$ \\
\hline & & & $(48.3 \pm 13)$ & $(89.7 \pm 16)$ & $(76 \pm 20)$ & $(55 \pm 14)$ & $(34 \pm 15)$ & $(3.4 \pm 13)$ \\
\hline \multirow[t]{2}{*}{3} & \multirow[t]{2}{*}{$\mathrm{mBM} 5+11 \mathrm{AA}$} & \multirow[t]{2}{*}{61} & $25 / 61^{\mathrm{a}}$ & $16 / 25$ & $14 / 25$ & $11 / 25^{\mathrm{ab}}$ & $9 / 25^{b c}$ & $1 / 25^{\mathrm{a}}$ \\
\hline & & & $(41 \pm 19)$ & $(64 \pm 20)$ & $(56 \pm 12)$ & $(44 \pm 10)$ & $(36 \pm 15)$ & $(4 \pm 8)$ \\
\hline \multirow[t]{2}{*}{4} & \multirow[t]{2}{*}{ mBM5+NEA } & \multirow[t]{2}{*}{61} & $37 / 61^{a b}$ & $33 / 37$ & 29/37 & $22 / 37^{a b}$ & $11 / 37^{b d}$ & $0 / 37^{a}$ \\
\hline & & & $(61 \pm 17)$ & $(89 \pm 13)$ & $(78 \pm 25)$ & $(59 \pm 15)$ & $(30 \pm 21)$ & $(0 \pm 0)$ \\
\hline \multirow[t]{2}{*}{5} & \multirow[t]{2}{*}{$\mathrm{mBM} 5+\mathrm{NEA}+\mathrm{GLN}$} & \multirow[t]{2}{*}{59} & $39 / 59^{b}$ & $32 / 39$ & $27 / 39$ & $22 / 39^{b}$ & $10 / 39^{b d}$ & $0 / 39^{a}$ \\
\hline & & & $(66 \pm 21)$ & $(82 \pm 17)$ & $(69 \pm 15)$ & $(56 \pm 20)$ & $(26 \pm 15)$ & $(0 \pm 0)$ \\
\hline \multirow[t]{2}{*}{6} & \multirow[t]{2}{*}{ mBM5+EA } & \multirow[t]{2}{*}{63} & $26 / 63^{a}$ & $20 / 26$ & $17 / 26$ & $10 / 26^{\mathrm{ab}}$ & $2 / 26^{\mathrm{a}}$ & $0 / 26^{a}$ \\
\hline & & & $(41 \pm 14)$ & $(77 \pm 19)$ & $(65 \pm 20)$ & $(38 \pm 24)$ & $(8 \pm 8)$ & $(0 \pm 0)$ \\
\hline \multirow[t]{2}{*}{7} & \multirow[t]{2}{*}{$\mathrm{mBM} 5+\mathrm{EA}+\mathrm{GLN}$} & \multirow[t]{2}{*}{61} & $36 / 61^{a b}$ & $28 / 36$ & $24 / 36$ & $11 / 36^{a}$ & 4/36 ade & $0 / 36^{a}$ \\
\hline & & & $(59 \pm 18)$ & $(78 \pm 21)$ & $(67 \pm 14)$ & $(31 \pm 25)$ & $(11 \pm 11)$ & $(0 \pm 0)$ \\
\hline \multirow[t]{2}{*}{8} & \multirow[t]{2}{*}{$\mathrm{mBM} 5+20 \mathrm{AA}+\mathrm{GLN}$} & \multirow[t]{2}{*}{61} & $34 / 61^{a b}$ & $32 / 34$ & $28 / 34$ & $22 / 34^{b}$ & $18 / 34^{c}$ & $6 / 34^{b}$ \\
\hline & & & $(56 \pm 19)$ & $(94 \pm 7)$ & $(82 \pm 11)$ & $(65 \pm 16)$ & $(53 \pm 21)$ & $(18 \pm 13)$ \\
\hline \multirow[t]{2}{*}{9} & \multirow[t]{2}{*}{ mCMRL-1066 } & \multirow[t]{2}{*}{61} & $26 / 61^{a}$ & $22 / 26$ & $20 / 26$ & $16 / 26^{\mathrm{ab}}$ & $10 / 26^{\text {be }}$ & $1 / 26^{a}$ \\
\hline & & & $(43 \pm 15)$ & $(84 \pm 14)$ & $(77 \pm 12)$ & $(62 \pm 25)$ & $(38 \pm 24)$ & $(3.8 \pm 13)$ \\
\hline
\end{tabular}

Data from seven replicates.

*Percentage of the number of oocytes cultured.

tPercentage of the number of oocytes at metaphase II.

a-eWithin a column, values (mean $\pm \mathrm{SD}$ ) with different superscripts are significantly different $(P<0.05)$.

mBM5: modified basic medium 5; GLN: glutamine; 11 AA:11 amino acids from hamster embryo culture medium 6; NEA: Eagles non-essential amino acids; EA: Eagle's essential amino acids; 20 AA: 20 amino acids; mCMRL: modified Connaught Medical Research Laboratories 1066 medium.

treatment eight (mBM5 + $20 \mathrm{AA}+$ glutamine) and $156 \mathrm{~h}$ in treatment 9 (mCMRL-1066) after insemination. Two of six blastocysts obtained in treatment 8 , and one of one in treatment 9 expanded fully. Because all blastocysts were used for other purposes, the hatching and number of cells of the blastocysts could not be determined in this study.

\section{Discussion}

The strategy for improving IVM and embryo development responses for mammalian oocytes is to customize the formulation of the culture medium according to the nutritional and metabolic requirements of the oocytes and embryos. Considerable progress has been made with 
oocytes and embryos in some species, including hamsters (McKiernan et al., 1991, 1995) and cows (Pinyopummintr and Bavister, 1996a,b; Rose-Hellekant et al., 1998). For customizing a culture medium, it is helpful to start with a minimal, laboratory-prepared culture medium and add components shown to improve development (Bavister, 1995). Modified BM5, a simple chemically defined medium (McKiernan and Bavister, 2000) supplemented with glucose, pantothenic acid, gonadotrophins, oestradiol and progesterone could support IVM of rhesus oocytes (Si et al., 2000; Zheng et al., 2001a). Therefore, this medium was used in the present study to investigate the effects of various amino acid formulations on maturation and subsequent embryonic development of rhesus monkey oocytes. The present study demonstrates that certain amino acids are required for the nuclear and cytoplasmic maturation of rhesus monkey oocytes. This result is in agreement with previous studies on non-primate species, including mice (Gardner and Lane, 1993), cows (Avery et al., 1998; RoseHellekant et al., 1998) and pigs (Jeong and Yang, 2001), which indicate that the inclusion of certain amino acids in the medium stimulates oocyte maturation and subsequent embryo development.

In the present study, essential amino acids with or without glutamine had no effect on nuclear and cytoplasmic maturation of rhesus monkey oocytes (treatments 6 and 7 versus treatment 1). Similarly, poor embryonic development was obtained with bovine oocytes matured in modified basic medium 3 supplemented with essential amino acids from TCM-199 (Avery et al., 1998). Culture in Eagle's essential amino acid in the absence of glutamine inhibited embryonic cleavage of mouse embryos (Gardner and Lane, 1993). This group of amino acids also contains all of the amino acids found to be most detrimental to hamster zygote development (Bavister and Arlotto, 1990; McKiernan et al., 1995). In contrast, essential amino acids have beneficial effects on mouse embryos after the eightcell stage of development in vitro (Lane and Gardner, 1997). Essential amino acids can be transported into the oocyte and embryo and are needed for protein synthesis and accumulation (Moor and Smith, 1979; Lane and Gardner, 1997; Van Winkle, 2001); some of them were effective signalling molecules (Patti et al., 1998; Shigemitsu et al., 1999). In the present study, essential amino acids stimulated cytoplasmic maturation of rhesus monkey oocytes when non-essential amino acids with glutamine were included in the medium (treatment 8 versus treatment 6). These differences could be attributed to differences in the types and concentrations of amino acids present, the developmental stage tested and the experimental design in different studies. It is noteworthy that when evaluating the action of certain amino acids, attention should be paid to the interactions among the components of a culture medium and the developmental stage examined (Partridge and Leese, 1996; Steeves and Gardner, 1999).

Inclusion of glutamine alone in the IVM medium could confer an intermediary benefit on the competence of rhesus monkey oocytes. A stimulatory role for glutamine in oocyte maturation and embryo development has been reported in cows (Pinyopummintr and Bavister, 1996a,b; Avery et al., 1998; Rose-Hellekant et al., 1998), pigs (Petters et al., 1990), rabbits (Bae and Foote, 1975a), mice (Chatot et al., 1989), hamsters (McKiernan et al., 1995) and humans (Devreker et al., 2001). Glutamine is readily taken up and metabolized by COCs and embryos (Bae et al., 1975b; Chatot et al., 1990; Zuelke and Brackett, 1993) and can function both as an energy source and as a precursor for macromolecules (Zielke et al., 1984; Newsholme et al., 1985; Rieger et al., 1992). Several studies on rabbit oocytes and bovine embryos demonstrate that glutamine is preferred, serving as an energy source to stimulate oocyte maturation and embryo development in vitro (Bae and Foote, 1975b; Rieger et al., 1992). However, in the present study, it was not known how glutamine conferred its benefit on rhesus monkey oocytes. Inclusion of essential amino acids in mBM5 plus glutamine appeared to reduce embryo development (treatments 7 versus 2), although this reduction was not significant. It appeared that the action of glutamine could be counteracted by essential amino acids. This was confirmed by the observation that cumulus expansion of COCs in mBM5 plus essential amino acids plus glutamine (treatment 7) was much poorer than that of COCs in mBM5 plus glutamine (treatment 2). Glutamine and cysteine share the same transport systems (Christensen, 1990), so the competitive transportation for these amino acids might be partially responsible for the negative relationship between glutamine and essential amino acids.

The embryo developmental potential of oocytes matured in mBM5 plus non-essential amino acids (treatment 4) was significantly better than that of oocytes matured in mBM5 or mBM5 plus essential amino acids (treatments 1 and 6, respectively), inferring a stimulatory role for the nonessential amino acids in maturation of rhesus monkey oocytes. Other studies have reported the expression and regulation of transport systems for non-essential amino acid in oocytes and preimplantation embryos (for a review, see Van Winkle, 2001). The beneficial effects of non-essential amino acids on oocyte maturation and preimplantation embryo development in vitro were demonstrated in several species, including cows (Pinyopummintr and Bavister, 1996b; Avery et al., 1998), mice (Gardner and Lane, 1993) and humans (Devreker et al., 2001). In vivo, almost all of these non-essential amino acids are present at high concentrations in the endogenous amino acid pool of oocytes and oviduct fluid (Schultz et al., 1981; Miller and Schultz, 1987). Taken together, these results indicate a common role for non-essential amino acids in mammalian oocyte maturation and early embryonic development. Nonessential amino acids are supposed to act through being utilized in protein synthesis, intracellular $\mathrm{pH}$ regulation (Bavister and McKiernan, 1993; Edwards et al., 1998), osmoregulation and cellular signalling (Dawson and Baltz, 1997; Van Winkle, 2001). However, the mechanism of action of non-essential amino acids in the present study is 
still unclear. The osmolalities of all the media were about $290 \mathrm{mOsmol} \mathrm{kg}^{-1}$ (normal range). Thus, it seems that the non-essential amino acids did not function as an organic osmolyte to benefit maturation of rhesus monkey oocytes.

The medium conferring the highest morula and blastocyst developmental capacity on rhesus monkey oocytes in culture was mBM5 plus Eagle's 20 amino acids plus glutamine (treatment 8 ). However, in other studies on IVM of bovine oocytes (Avery et al., 1998), and bovine and mouse embryo development in vitro (Gardner and Lane, 1993; Pinyopummintr and Bavister, 1996b), the effect of non-essential amino acids was similar or significantly better than that of non-essential amino acids plus essential amino acids. This discrepancy might be due to a species-specific or stage-specific requirement for amino acids during oocyte maturation and embryo development. Eagle's 20 amino acids with glutamine (treatment 8 ) functioned better than non-essential amino acids (treatment 4) or essential amino acids with glutamine (treatment 7 ) in IVM of rhesus monkey oocytes. Obviously, there were some positive interactions between the two groups. Interactions among amino acids have been reported (Bavister and Arlotto, 1990; Steeves and Gardner, 1999). However, it is difficult to deduce the mechanism responsible.

In the culture medium (containing gonadotrophins and glucose) used in the present study, inclusion of different groups of amino acids in IVM medium resulted in various extents of cumulus expansion. This finding implies a requirement for certain amino acids in cumulus expansion of rhesus monkey COCs. The COCs matured in mBM5 plus essential amino acids (treatment 6) displayed minimal cumulus expansion of category 1 as did those matured in mBM5 (treatment 1), indicating no action of essential amino acids on cumulus expansion of rhesus monkey COCs. Glutamine is a metabolic precursor for hexosamine synthesis and its inclusion in culture medium improves cumulus expansion of hamster and bovine COCs (Chen et al., 1990; Kito and Bavister, 1997; Avery et al., 1998; RoseHellekant et al., 1998) as well as rhesus monkey COCs in the present study. Besides glutamine, non-essential amino acids were able to induce some degree of cumulus expansion in rhesus monkey COCs. Similarly, Avery et al. (1998) reported the effect of non-essential amino acids from TCM199 on cumulus expansion of bovine COCs. Because the response of cumulus expansion was similar among mBM5 plus glutamine (treatment 2), mBM5 plus 11 amino acids from hamster embryo culture medium 6 (treatment 3), mBM5 plus non-essential amino acids plus glutamine (treatment 5) and mBM5 plus Eagle's 20 amino acids plus glutamine (treatment 8 ), it seems that cumulus expansion does not require non-essential amino acids in the presence of glutamine, so the beneficial effect of 11 amino acids as from hamster embryo culture medium as well as Eagle's 20 amino acids on cumulus expansion of rhesus monkey COCs can be attributed to glutamine. The COCs with very little cumulus expansion that were matured in treatments 1 (mBM5 no amino acids), 6 (mBM5 plus essential amino acids) and 7 (mBM5 plus essential amino acids plus glutamine) had the poorest developmental competence, and COCs with better cumulus expansion showed improved developmental competence (treatments 2, 3, 4, 5, 8, and 9). However, the COCs with similar developmental competence that were matured in $\mathrm{mBM} 5$ containing glutamine, 11 amino acids from hamster embryo culture medium, nonessential amino acids, non-essential amino acids plus glutamine or mCMRL-1066 (treatment 2, 3, 4, 5, and 9, respectively) displayed different cumulus expansion, and vice versa. Thus, it can be concluded that although the acquisition of developmental competence of rhesus monkey COCs in vitro may require at least moderate cumulus expansion, these events are not closely correlated with each other. This result confirms the conclusion of Rose-Hellekant et al. (1998) and Zheng et al. (2001a). However, in our previous study with COCs from FSH-stimulated rhesus monkeys, the acquisition of developmental potential did not require moderate cumulus expansion (Zheng et al., 2001b). This discrepancy might be due to the different animal treatment as well as to use of different culture systems in the two studies.

In summary, the results obtained from the present study demonstrate that the choice of amino acids included in IVM culture media affects developmental competence of oocytes. In our current culture medium, Eagle's 20 amino acids with $0.2 \mathrm{mmol}$ glutamine $\mathrm{I}^{-1}$ is more efficient than the other amino acid formulations for maturation of rhesus monkey oocyte. Further detailed investigations should be conducted to establish the optimal amino acid requirements for oocyte maturation. The results of these studies are anticipated to benefit assisted reproductive technology and conservation of endangered species as well as transgenic biotechnology and basic research.

This research was supported by the Major State Research Development Program G2000016108 and the key project of the Chinese Academy of Sciences, KSCX 1-05-01.

\section{References}

Abeydeera LR, Wang WH, Cantley TC, Rieke A, Murphy CN, Prather RS and Day BN (2000) Development and viability of pig oocytes matured in a protein-free medium containing epidermal growth factor Theriogenology 54 787-797

Avery B, Bavister BD and Greve T (1998) Development of bovine oocytes, in vitro matured in a chemically defined protein-free medium, supplemented with different amino acid formulations Theriogenology 49306 (Abstract)

Bae IH and Foote RH (1975a) Carbohydrate and amino acid requirements and ammonia production of rabbit follicular oocytes matured in vitro. Experimental Cell Research 91 113-118

Bae IH and Foote RH (1975b) Utilization of glutamine for energy and protein synthesis by cultured rabbit follicular oocytes Experimental Cell Research 90 432-436

Barnes FL, Crombie A, Gardner DK, Kausche A, Lacham-Kaplan O, Suikkari AM, Tiglias J, Wood C and Trounson AO (1995) Blastocyst development and birth after in vitro maturation of human primary oocytes, intracytoplasmic sperm injection and assisted hatching Human Reproduction $103243-3247$ 
Bavister BD (1989) A consistently successful procedure for in vitro fertilization of golden hamster eggs Gamete Research 23 139-158

Bavister BD (1995) Culture of preimplantation embryos: facts and artefacts Human Reproduction Update 1 91-148

Bavister BD and Arlotto T (1990) Influence of single amino acids on the development of hamster one-cell embryos in vitro. Molecular Reproduction and Development 25 45-51

Bavister BD and McKiernan SH (1993) Regulation of hamster embryo development in vitro by amino acids. In Preimplantation Embryo Development pp 57 Ed. BD Bavister. Springer-Verlag Press, New York

Bavister BD, Boatman DE, Leibfried L, Loose M and Vernon MW (1983) Fertilization and cleavage of rhesus monkey oocytes in vitro. Biology of Reproduction 28 983-999

Boatman DE (1987) In vitro growth of non-human primate pre- and periimplantation embryos. In Mammalian Preimplantation Embryos. Regulation of Growth and Differentiation pp 273-308 Ed. BD Bavister. Plenum Press, New York

Boatman DE and Bavister BD (1984) Stimulation of rhesus monkey sperm capacitation by cyclic nucleotide mediators Journal of Reproduction and Fertility 71 357-366

Cha KY, Koo JJ, Ko JJ, Choi DH, Han SY and Yoon TK (1991) Pregnancy after in vitro fertilization of human follicular oocytes collected from nonstimulated cycles, their culture in vitro and their transfer in a donor oocyte program Fertility and Sterility 55 109-113

Chatot CL, Ziomek CA, Bavister BD, Lewis JL and Torres I (1989) An improved culture medium supports development of random-bred 1-cell mouse embryos in vitro. Journal of Reproduction and Fertility 86 679-688

Chatot CL, Tasca RI and Ziomek CA (1990) Glutamine uptake and utilization by preimplantation mouse embryos in CZB medium Journal of Reproduction and Fertility 89 335-346

Chen L, Wert SE, Hendrix EM, Russell PT, Cannon M and Larsen WJ (1990) Hyaluronic acid synthesis and gap junction endocytosis are necessary for normal expansion of the cumulus mass Molecular Reproduction and Development 26 236-247

Christensen HN (1990) Role of amino acid transport and countertransport in nutrition and metabolism Physiological Reviews $7043-77$

Dawson KM and Baltz JM (1997) Organic osmolytes and embryos: substrates of the Gly and $\beta$ transport systems protect mouse zygotes against the effects of raised osmolarity Biology of Reproduction 56 1550-1558

De La Fuente R, O'Brien MJ and Eppig JJ (1999) Epidermal growth factor enhances preimplantation developmental competence of maturing mouse oocytes Human Reproduction 14 3060-3068

Devreker F, Hardy K, Van den Bergh M, Vannin AS, Emiliani S and Englert $\mathbf{Y}$ (2001) Amino acids promote human blastocyst development in vitro. Human Reproduction 16 749-756

Eagle H (1959) Amino acid metabolism in mammalian cell cultures Science $130432-437$

Edwards LJ, Williams DA and Gardner DK (1998) Intracellular pH of the mouse preimplantation embryo: amino acids act as buffers of intracellular pH Human Reproduction 13 3441-3448

Eppig JJ, Schultz RM, O'Brien M and Chesnel F (1994) Relationship between the developmental programs controlling nuclear and cytoplasmic maturation of mouse oocytes Developmental Biology 164 $1-9$

Gardner DK and Lane M (1993) Amino acids and ammonium regulate mouse embryo development in culture Biology of Reproduction $\mathbf{4 8}$ 377-385

Gould KG and Mann DR (1988) Comparison of electrostimulation methods for semen recovery in rhesus monkey (Macaca mulatta) Journal of Medical Primatology 17 95-103

Guler A, Poulin N, Mermillod P, Terqui M and Cognie Y (2000) Effect of growth factors, EGF and IGF-I, and estradiol on in vitro maturation of sheep oocytes Theriogenology 54 209-218

Jeong BS and Yang X (2001) Cysteine, glutathione and Percoll treatments improve porcine oocyte maturation and fertilization in vitro. Molecular Reproduction and Development 59 330-335

Kito S and Bavister BD (1997) Gonadotropins, serum and amino acids alter nuclear maturation, cumulus expansion and oocyte morphology in hamster cumulus-oocyte complexes in vitro. Biology of Reproduction 56 1281-1289

Lane $\mathbf{M}$ and Gardner DK (1997) Differential regulation of mouse embryo development and viability by amino acids Journal of Reproduction and Fertility 109 153-164

Lane M, Boatman DE, Albrecht RM and Bavister BD (1998) Intracellular divalent cation homeostasis and developmental competence in the hamster preimplantation embryo Molecular Reproduction and Development 50 443-450

McKiernan SH and Bavister BD (2000) Culture of one-cell hamster embryos with water soluble vitamins: pantothenate stimulates blastocyst production Human Reproduction 15 157-164

McKiernan SH, Bavister BD and Tasca RJ (1991) Energy substrate requirements for in vitro development of hamster 1- and 2-cell embryos to the blastocyst stage Human Reproduction 6 64-75

McKiernan SH, Clayton MK and Bavister BD (1995) Analysis of stimulatory and inhibitory amino acids for development of hamster one-cell embryos in vitro Molecular Reproduction and Development 42 188-199

Miller JG and Schultz GA (1987) Amino acid content of preimplantation rabbit embryos and fluids of the reproductive tract Biology of Reproduction 36 125-129

Moor RM and Smith MW (1979) Amino acid transport in mammalian oocytes Experimental Cell Research 119 333-341

Morgan PM, Boatman EE and Bavister BD (1991) In vitro maturation of ovarian oocytes from unstimulated rhesus monkeys: assessment of cytoplasmic maturity by embryonic development after in vitro fertilization Biology of Reproduction 45 89-93

Newsholme EA, Crabtree B and Ardawi MS (1985) The role of high rates of glycolysis and glutamine utilization in rapidly dividing cells Bioscience Reports 5 393-400

Partridge RJ and Leese HJ (1996) Consumption of amino acids by bovine preimplantation embryos Reproduction, Fertility and Development 8 945-950

Patti ME, Brambilla E, Luzi L, Landaker EJ and Kahn CR (1998) Bidirectional modulation of insulin action by amino acids Journal of Clinical Investigation 101 1519-1529

Petters RM, Johnson BH, Reed ML and Archibong AE (1990) Glucose, glutamine and inorganic phosphate in early development of the pig embryo in vitro. Journal of Reproduction and Fertility 89 269-275

Pinyopummintr T and Bavister BD (1996a) Energy substrate requirements for in vitro development of early cleavage-stage bovine embryos Molecular Reproduction and Development 44 193-199

Pinyopummintr T and Bavister BD (1996b) Effects of amino acids on in vitro development of cleavage stage bovine embryos into blastocysts Reproduction, Fertility and Development 8 835-841

Rieger D, Loskutoff NM and Betteridge KJ (1992) Developmentally related changes in the metabolism of glucose and glutamine by cattle embryos produced and co-cultured in vitro. Journal of Reproduction and Fertility 95 585-595

Rose-Hellekant TA, Libersky-Williamson EA and Bavister BD (1998) Energy substrates and amino acids provided during in vitro maturation of bovine oocytes alter acquisition of developmental competence Zygote 6 285-294

Schramm RD and Bavister BD (1996) Granulosa cells from folliclestimulating hormone-primed monkeys enhance developmental competence of in vitro matured oocytes from nonstimulated rhesus monkeys Human Reproduction 11 1698-1702

Schultz GA, Kaye PL, McKay DJ and Johnson MH (1981) Endogenous amino acid pool sizes in mouse eggs and preimplantation embryos Journal of Reproduction and Fertility 61 387-393

Shigemitsu K, Tsujishita Y, Miyake H, Hidayat S, Tanaka N, Hara K and Yonezawa K (1999) Structural requirement of leucine for activation of p70 S6 kinase FEBS Letters 447 303-306

Si W, Zheng P, Bavister BD and Ji WZ (2000) Effects of progesterone and $17 \beta$-estradiol on in vitro maturation of oocytes from unstimulated adult and prepubertal rhesus monkeys Biology of Reproduction 62 Supplement 1160

Steeves TE and Gardner DK (1999) Temporal and differential effects of 
amino acids on bovine embryo development in culture Biology of Reproduction $61731-740$

Vanderhyden BC and Armstrong DT (1990) Effects of gonadotrophins and granulosa cell secretions on the maturation and fertilization of rat oocytes in vitro. Molecular Reproduction and Development 26 337-346

Van Winkle LJ (2001) Amino acid transport regulation and early embryo development Biology of Reproduction 64 1-12

Watson AJ, De Sousa P, Caveney A, Barcroft LC, Natale D, Urquhart J and Westhusin ME (2000) Impact of bovine oocyte maturation media on oocyte transcript levels, blastocyst development, cell number and apoptosis Biology of Reproduction 62 355-364

Wolf DP, Vandevoort CA, Meyer-Haas GR, Zelinski-Wooten MB, Hess DL, Baughman WL and Stouffer RL (1989) In vitro fertilization and embryo transfer in the rhesus monkey Biology of Reproduction 41 335-346

Zheng P, Bavister BD and Ji WZ (2001a) Energy substrate requirement for in vitro maturation of oocytes from unstimulated adult rhesus monkeys Molecular Reproduction and Development 58 348-355
Zheng P, Wang H, Bavister BD and Ji WZ (2001b) Maturation of rhesus monkey oocytes in chemically defined culture media and their functional assessment by IVF and embryo development Human Reproduction 16 300-305

Zielke HR, Zielke CL and Ozand PT (1984) Glutamine: a major energy source for cultured mammalian cells Federation Proceedings $\mathbf{4 3}$ 121-125

Zuelke KA and Brackett BG (1993) Increased glutamine metabolism in bovine cumulus cell-enclosed and denuded oocytes after in vitro maturation with luteinizing hormone Biology of Reproduction 48 815-820

Received 11 March 2002

First decision 23 May 2002

Revised manuscript received 29 May 2002.

Accepted 3 July 2002. 